\title{
Avaliação de espécies leguminosas na formação de cafezais no segmento da agricultura familiar no Acre
}

\author{
Celso Luis BERGO ${ }^{1}$, Edson Patto PACHECO ${ }^{2}$, Hélia Alves de MENDONÇA ${ }^{3}$, \\ José Tadeu de Souza MARINHO ${ }^{4}$
}

\begin{abstract}
RESUMO
Leguminosas quando consorciadas com o café e usadas como adubação verde podem contribuir fornecendo nitrogênio e proteção ao solo pela adição de matéria orgânica. $O$ trabalho foi conduzido com o objetivo de avaliar o efeito do uso de leguminosas no sistema de produção de café, no segmento de agricultura familiar, visando promover a implantação e a manutenção dos cafezais de forma técnica e economicamente sustentável. O experimento foi conduzido no período de novembro de 2000 a abril de 2003, em delineamento experimental de blocos ao acaso em esquema de parcelas subdivididas, com quatro repetições. Os tratamentos utilizados nas parcelas foram as leguminosas (Stizolobium atterrimum, Cajanus cajan, Canavalia endiformis e Flemingia congesta) e a testemunha (sem leguminosa) e, nas subparcelas, duas doses de $\mathrm{N}$ ( 0 e $22 \mathrm{~g}$ de $\mathrm{N}$ por cova). A Flemingia congesta e a Mucuna aterrima foram as leguminosas que mais influenciaram positivamente a produtividade dos cafeeiros, independente da adubação nitrogenada. Em relação à testemunha, o aumento em produção foi de $109 \%$ quando utilizou-se a Flemingia congesta e 52\% com a Mucuna aterrima. A Flemingia congesta foi também a leguminosa que melhor controlou as invasoras, dado o volume de fitomassa produzida e a possibilidade de 2 cortes durante um período de doze meses, evidenciando o potencial desta leguminosa na formação de novos cafezais no Acre. Por outro lado, a Canavalia ensiformis, leguminosa que é normalmente utilizada nas entrelinhas dos cafeeiros pelos cafeicultores, do Acre e de outras regiões produtoras, neste trabalho influenciou negativamente a altura das plantas, diâmetro da copa e crescimento dos cafeeiros.
\end{abstract}

\section{PALAVRAS-CHAVE}

Amazônia, Coffea arabica, café, leguminosas, consórcio.

\section{Evaluation of legume species for coffee plants formation in the segment of family farms in Acre.}

\begin{abstract}
Legumes, when associated with coffee crop and used as green manure can contribute with nitrogen and protect the soil by addition of organic matter. The effect of the use legume species in the coffee production system of family farms, was evaluated in order to promote the implantation and maintenance of coffee plantations. The experiment was carried out from November 2000 to April 2003. The experimental delineation was by randomized blocks in subdivided plots, utilizing the legumes Stizolobium atterrimum, Cajanus cajan, Canavalia endiformis, Flemingia congesta, and the control (without legumes) in plots, 0 and $22 \mathrm{~g}$ of $\mathrm{N}$ dosage in each hole in the subplots. The Flemingia congesta and the Stizolobium atterrimum were the species that most influenced the productivity of the coffee plants, independently of the nitrogen fertilization. In relation to the control; this productivity increased 109\% greater when Flemingia congesta was used and 52\% for Stizolobium atterrimum. The Flemingia congesta provided the best weed control, given the volume of matter produced, providing of two cuttings during a twelve months period. These results showed the potential of this legume species in the formation of new coffee crops in Acre State.

Canavalia endiformis legume negatively influenced height, crown diameter and growth of the coffee plant contradicting the practice of using in the coffee crops in Acre and in other areas.
\end{abstract}

\section{KEYWORDS}

Amazon, Coffea arabica, coffee, leguminosae, consortium.

\footnotetext{
${ }^{1}$ Embrapa Acre, celso@cpafac.embrapa.br

${ }^{2}$ Embrapa Tabuleiros Costeiros, patto@cpatc.embrapa.br

${ }^{3}$ EmbrapaAcre, helia@cpafac.embrapa.br

${ }^{4}$ EmbrapaAcre, tadeu@cpafac.embrapa.br
} 


\section{INTRODUÇÃO}

As condições edafoclimáticas do Acre, caracterizadas por altas temperaturas, solos argilosos com camadas compactadas e precipitações pluviométricas que favorecem a erosão do solo, lixiviação dos nutrientes e a mineralização rápida da matéria orgânica podem reduzir a produtividade e longevidade dos cafezais, além de aumentar os custos de formação e manutenção das lavouras em função da maior demanda de mão-de-obra para controle de invasoras e da necessidade de adubação para repor os nutrientes perdidos e exportados pela produção. Diante desse quadro tornam-se necessários estudos mais adequados com relação às práticas de cultivo, entre elas o consórcio de leguminosas nas entrelinhas dos cafeeiros como cobertura do solo, controle de invasoras e adubação verde.

O uso de leguminosas é uma prática conservacionista que utiliza a própria vegetação para proteger o solo da erosão. Outro grande benefício do seu uso é a produção de matéria orgânica que, através de sua incorporação, estimula diversos processos químicos e biológicos melhorando sua fertilidade (Bertoni \& Neto, 1993).

Estudos realizados em Rio Branco - Acre, fazendo uso da Mucuna aterrima, sobre as perdas de solo e água em um Podzólico Vermelho-Escuro, mostraram que, enquanto no tratamento em pousio descoberto houve perda de 10.043,6 $\mathrm{kg} / \mathrm{ha}$ de solo, na parcela coberta com cultivo de Mucuna aterrima as perdas foram de $32,4 \mathrm{~kg} / \mathrm{ha}$, controlando a erosão em $99,7 \%$ e retendo $97,5 \%$ do total hídrico erosivo precipitado (Gomes et al., 1990).

Ricci \& Aguiar (2003) avaliando a influência da leguminosa Cajanus cajan sobre o crescimento e produtividade do cafeeiro arábica, sob manejo orgânico, mostraram a importância dessa associação no significativo aporte de $\mathrm{N}$, de matéria orgânica além de outros nutrientes no agroecossistema. Referem-se principalmente ao $\mathrm{N}$, cuja concentração em outras fontes orgânicas usadas na adubação dos cafeeiros normalmente é baixa para suprir as necessidades, como a casca do café, com um teor de $\mathrm{N}$ variando de 0,6 a $1,2 \%$ ou o esterco bovino, variando de 0,3 a 3,5\% (Vale et al., 1995). Os teores de $\mathrm{N}$ considerados ideais nas folhas dos cafeeiros variam de 2,7 a $3,2 \%$ (Andrade, 2001). Nos testes realizados com Cajanus cajan, Ricci \& Aguiar (2003) constataram um teor médio de N nas folhas dos cafeeiros de 3,3\% na presença dessa leguminosa nas entrelinhas, contra 2,7\% obtido em sua ausência.

Em experimentos conduzidos na Colômbia, com Flemingia congesta como planta de cobertura nas entrelinhas de cafeeiros jovens e adultos, Carvajal (1984) demonstrou que a produtividade desses cafeeiros aumentou de 60 a 200\%, induzindo ainda a um início de produção mais precoce nos cafeeiros jovens. Gomes \& Moraes (1997), em suas recomendações para plantio de espécies leguminosas para o manejo de solos no Acre, indicaram a Flemingia congesta como a mais produtiva e também como alternativa para manejo e recuperação dos solos tropicais, principalmente para regiões geograficamente mais distantes dos grandes mercados de insumos, devido ao preço elevado dos fertilizantes químicos.
Guimarães et al. (2002) avaliando o efeito do consórcio Canavalia ensiformis $\mathrm{x}$ café, plantado no espaçamento $4,0 \mathrm{~m}$ $\mathrm{x} 1,0 \mathrm{~m}$, semearam anualmente em suas entrelinhas 6, 4, 2 e 0 linhas desta leguminosa no espaçamento de $0,50 \mathrm{~m}$ entre plantas a partir do primeiro ano e obtiveram respectivamente, $5,16,18$ e 29 sacas de café beneficiado por ha na primeira colheita demonstrando assim a influência prejudicial desta leguminosa sobre os cafeeiros e sua produção. Os autores acima concluíram que pode ter havido algum efeito alelopático negativo do Canavalia ensiformis sobre o cafeeiro, sugerindo que esta leguminosa seja plantada somente antes da implantação da lavoura cafeeira. Por outro lado Brasil (2000) recomenda seu plantio nas entrelinhas dos cafeeiros no espaçamento de $50 \mathrm{~cm}$ entre linhas e $20 \mathrm{~cm}$ entre plantas.

Almeida e Rodrigues (1985), citado por Monegat (1991), afirmam que existe uma relação entre a quantidade de cobertura morta produzida e a redução da infestação por plantas daninhas e que, de maneira geral, as plantas de cobertura realizam supressão de plantas daninhas por meio de dois processos: "abafamento" e alelopatia. No caso do "abafamento", o controle é influenciado, além do sombreamento, pelos seguintes aspectos das plantas de cobertura: agressividade inicial, volume de massa verde e seca, porte (ereto ou prostado), distribuição dos resíduos sobre o terreno e velocidade de decomposição (relação C/N).

O objetivo desse trabalho foi o de avaliar o efeito do uso de leguminosas na cafeicultura familiar como alternativa para sua implantação e manutenção.

\section{MATERIAL E MÉTODOS}

O experimento foi conduzido no campo experimental da Embrapa Acre, localizado no $\mathrm{km} 14$ da rodovia BR 364, no município de Rio Branco - AC, com $160 \mathrm{~m}$ de altitude, latitude $9^{\circ} 58^{\prime} 22^{\prime \prime S}$, longitude $67^{\circ} 48^{\prime} 40^{\prime \prime W G r}$, com precipitação anual entre 1800 e $1900 \mathrm{~mm}$, temperatura média de $25^{\circ} \mathrm{C}$ e umidade relativa média de $85 \%$.

Para sua implantação foi selecionada uma área de pastagem com braquiarão cujo solo foi classificado como latossolo vermelho amarelo e apresentou as seguintes características físicas e químicas: textura média com $23 \%$ de argila, $\mathrm{pH}=5,2$ $\left(\mathrm{H}_{2} \mathrm{O}\right) ; \mathrm{P}=2 \mathrm{mg} / \mathrm{dm}^{3} ; \mathrm{K}=27 \mathrm{mg} / \mathrm{dm}^{3} ; \mathrm{Ca}=1,3 \mathrm{cmol} / \mathrm{dm}^{3} ; \mathrm{Mg}$ $=0,6 \mathrm{cmol} / \mathrm{dm}^{3} ; \mathrm{Al}=0,0 \mathrm{cmol} / \mathrm{dm}^{3} ; \mathrm{C} \%=0,98 \mathrm{dag} / \mathrm{kg}$. Após a calagem com 1 ton/ha de calcário magnesiano com PRNT = $75 \%$, foi feito o preparo do solo com duas gradagens pesadas e duas gradagens leves. Para o plantio das mudas foram abertos sulcos no terreno com espaçamento de $4 \mathrm{~m}$. A adubação fosfatada e potássica foi feita em linha, nos sulcos, conforme recomendação para implantação de cafezais da $4^{\mathrm{a}}$ Aproximação de Minas Gerais (Lopes et al., 1989).

Na implantação do cafezal, em novembro de 2000, foi utilizado a cultivar Icatu PR 182039-1 (H4782-7-788) com espaçamento de 4,0 m entre fileiras e 0, $8 \mathrm{~m}$ entre covas, com uma planta por cova.

O delineamento experimental foi em blocos ao acaso em 


\section{ACTA \\ AMAZONICA}

AVALIAÇÃO DE ESPÉCIES LEGUMINOSAS NA FORMAÇÃO DE CAFEZAIS

NO SEGMENTO DA AGRICULTURA FAMILIAR NO ACRE esquema de parcelas subdivididas com quatro repetições. Cada bloco constou de onze fileiras de café com $20 \mathrm{~m}$ de comprimento $(20 \mathrm{~m} \times 40 \mathrm{~m})$, perfazendo uma área total de 800 $\mathrm{m}^{2}$ por bloco. Os tratamentos utilizados nas parcelas foram as leguminosas e a testemunha (sem leguminosa) e nas subparcelas, adubação nitrogenada, 0 e $22 \mathrm{~g} / \mathrm{N}$ (uréia) por cova, aplicadas em cobertura, sendo metade no início do período chuvoso (novembro) e a outra metade no final (março), compondo-se os seguintes tratamentos:

1 - Consórcio café x mucuna preta (Mucuna aterrima) sem adubação

2 - Consórcio café x mucuna preta + adubação nitrogenada

3 - Consórcio café x flemingia (Flemingia congesta) sem adubação

4 - Consórcio café x flemingia + adubação nitrogenada

5 - Consórcio café x feijão de porco (Canavalia ensiformis) sem adubação

6 - Consórcio café x feijão de porco + adubação nitrogenada

7 - Consórcio café x guandu (Cajanus cajan) sem adubação

8 - Consórcio café $x$ guandu + adubação nitrogenada

9 - Testemunha : Café solteiro sem adubação

10 - Testemunha; Café solteiro + adubação nitrogenada

As parcelas foram compostas por duas entrelinhas com 4 $\mathrm{m}$ de largura e $20 \mathrm{~m}$ de comprimento, sendo as avaliações efetuadas em uma fileira de café, cercada pelos dois lados por um determinado tratamento.

Utilizou-se cinco linhas para cada leguminosa com covas distanciadas de $50 \mathrm{~cm}$ e densidade de 2 a 3 sementes por cova. $\mathrm{O}$ plantio das leguminosas foi efetuado anualmente em novembro, no início do período chuvoso, e o corte e distribuição da fitomassa sobre o solo no final deste período, em abril. A exceção foi para a Flemingia congesta, que dado a sua capacidade de rebrote pós recepa, recebeu anualmente 2 cortes, sem necessidade de replantio.

Para avaliação dos tratamentos foram consideradas os seguintes variáveis:

a) Produtividade dos cafeeiros em sua primeira colheita economicamente significativa: 2 anos e 5 meses pós plantio;

b) Altura e diâmetro da copa dos cafeeiros;

c) Fertilidade do solo, monitorada por análise das amostras coletadas no centro das entrelinhas, nas profundidades de 0 a $20 \mathrm{~cm}$;

d) Efeito das leguminosas na incidência de plantas invasoras: análise realizada em dois quadros de $1 \mathrm{~m}^{2}$ por tratamento, no centro das entrelinhas, onde foram coletadas as plantas invasoras e determinado seu peso seco.

Como as amostras, para as avaliações das variáveis dos itens "c" e "d", foram coletadas no centro das entrelinhas dos cafeeiros, distantes da "saia" do cafeeiro, onde foram realizadas as adubações nitrogenadas em cobertura, as análises estatísticas foram realizadas como blocos ao acaso desconsiderando-se as subdivisões das parcelas.
Também foi feita uma análise das folhas dos cafeeiros para avaliação dos percentuais médios de $\mathrm{N}$.

\section{RESULTADOS E DISCUSSÃO}

Verificou-se que houve diferença significativa $(\mathrm{P}<0,01)$ para as características produtividade; altura de plantas e diâmetro das copas dos cafeeiros, em função dos efeitos das leguminosas utilizadas nas entrelinhas dos cafeeiros (Figuras 1, 2 e 3) e ainda para incidência de plantas invasoras.

Quanto à adubação nitrogenada os resultados médios apresentaram diferenças significativas $(\mathrm{P}<0,01)$ para altura $\mathrm{e}$ diâmetro da copa, sendo maiores quando as plantas foram adubadas, mas não houve efeito na produtividade dos cafeeiros.

Apesar do efeito significativo das leguminosas, não houve interação entre elas e a adubação, indicando que as leguminosas apresentam os mesmos efeitos independentemente da adubação nitrogenada.

A Flemingia congesta proporcionou aos cafeeiros uma produtividade média de 9,56 sc de $60 \mathrm{~kg} / \mathrm{ha}$, sendo significativamente superior aos tratamentos Cajanus cajan, Canavalia ensiformis e a testemunha (Figura 1). Em relação à parcela testemunha o aumento em produtividade com a utilização da Flemingia congesta foi de $98 \%$. Estes resultados mostram o potencial que esta leguminosa apresenta juntamente com a Mucuna aterrima (que já vem sendo usada pelos cafeicultores acreanos) na formação de novos cafezais. Este potencial da Flemingia congesta também foi constatado na Colômbia por Carvajal (1984) que conseguiu, consorciando esta leguminosa com cafeeiros em produção, um aumento médio de produtividade de $130 \%$,

A leguminosa Canavalia ensiformis, além da influência negativa no diâmetro da copa dos cafeeiros, na sua altura e consequentemente no seu vigor, foi o tratamento que apresentou menor produtividade média, somente 1,03 sc de $60 \mathrm{~kg} / \mathrm{ha}$ (Figura 1). Estes resultados contrariam as recomendações de seu uso nas entrelinhas dos cafeeiros feita por Brasil (2000). Esta concorrência, observada no experimento, e refletida na produtividade dos cafeeiros, também foi observada por Guimarães et al. (2002), que obtiveram produtividade de 29 sacas de café beneficiado por hectare na ausência da Canavalia ensiformis, contra 5 sacas no tratamento com a Canavalia ensiformis. O referido autor atribuiu este fato a um provável efeito alelopático negativo da Canavalia ensiformis sobre os cafeeiros, recomendando que ele seja usado apenas como adubo verde antes da implantação da lavoura cafeeira.

Quando a variável analisada foi altura (Figura 2) de plantas, os melhores tratamentos médios foram a testemunha $\mathrm{e}$ Flemingia congesta com $142 \mathrm{~cm}$ e $136 \mathrm{~cm}$ respectivamente. As plantas que receberam adubação apresentaram uma altura média de $125 \mathrm{~cm}$, contra $107 \mathrm{~cm}$ daquelas não adubadas. Quando a variável analisada foi diâmetro da copa (Figura 3), os melhores resultados médios também foram obtidos nos tratamentos testemunha e Flemingia congesta, com $131 \mathrm{~cm}$ e $116 \mathrm{~cm}$ respectivamente. As plantas que receberam adubação 
nitrogenada apresentaram um diâmetro médio de copa 111 $\mathrm{cm}$, superando os $93 \mathrm{~cm}$ daquelas não adubadas.

Observou-se ainda que, a Canavalia ensiformis foi a que mais influenciou negativamente os cafeeiros, resultando numa altura $41 \%$ e $38 \%$ menores em relação aos melhores tratamentos (Testemunha e Flemingia congesta), respectivamente e, em $45 \%$ e $38 \%$ quando se tratou da variável diâmetro da copa (Figuras $2 \mathrm{e} 3$ ).

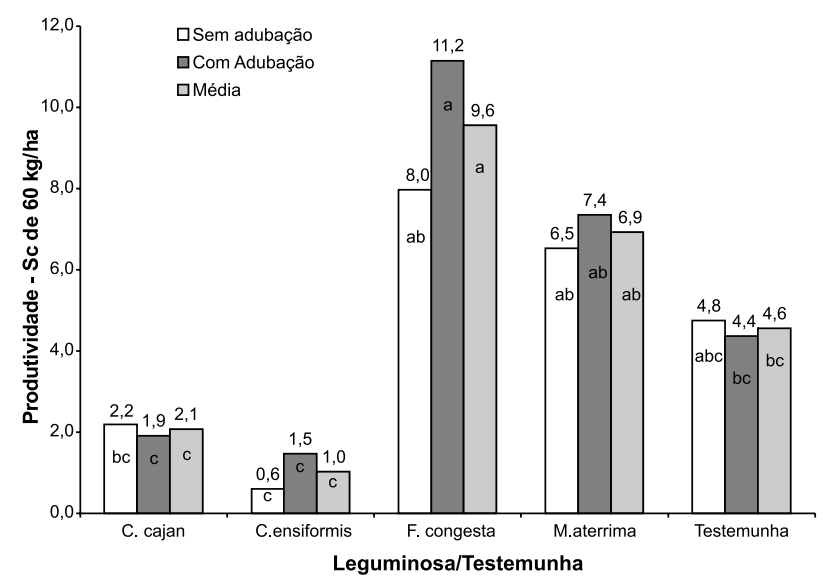

Figura 1 - Efeito do consórcio café x leguminosas na produtividade dos cafeeiros, Rio Branco, AC, 2003*

* Primeira colheita economicamente significativa -2 anos e 5 meses pós plantio. Médias seguidas de mesma letra nas colunas, não diferem entre si, pelo teste de Tukey, a 5\% de probabilidade.

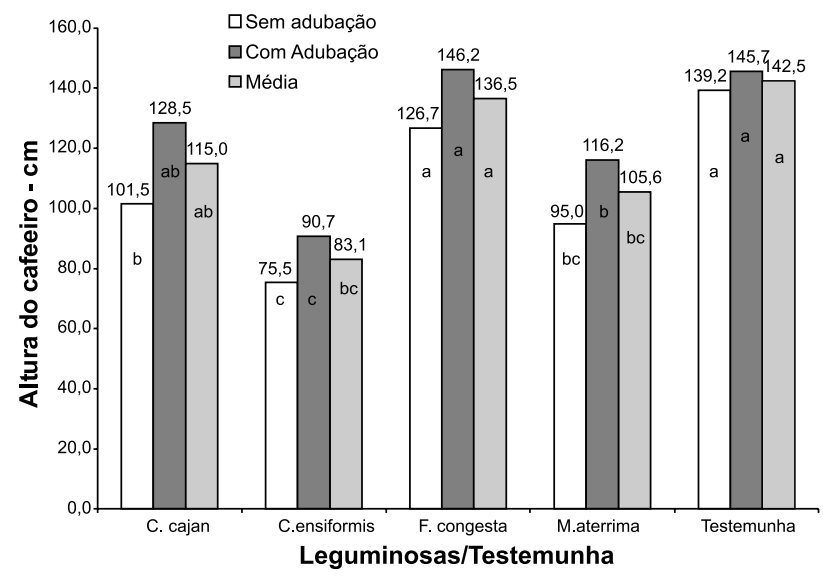

Figura 2 - Efeito do consórcio café x leguminosas na altura dos cafeeiros, Rio Branco, AC, 2003. Médias seguidas de mesma letra nas colunas, não diferem entre si, pelo teste de Tukey, a $5 \%$ de probabilidade.

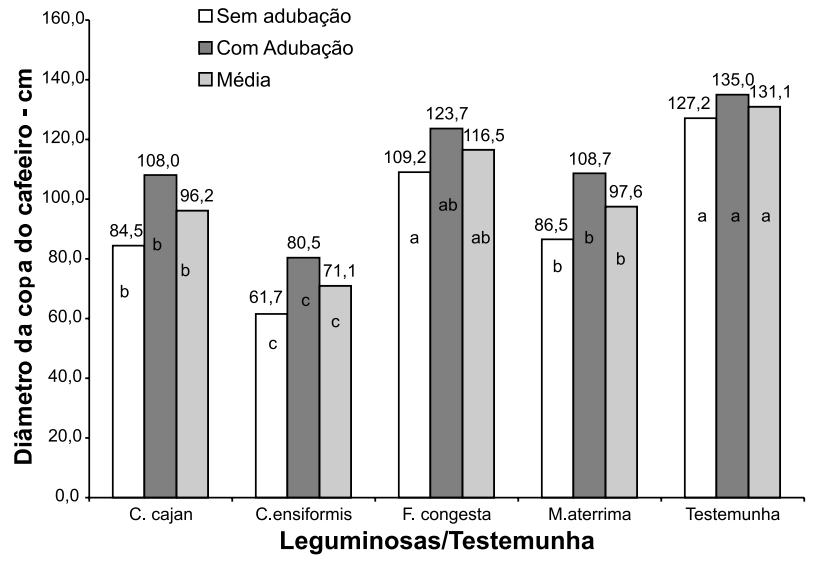

Figura 3 - Efeito do consórcio café $\mathrm{x}$ leguminosas no diâmetro da copa dos cafeeiros, Rio Branco, AC, 2003. Médias seguidas de mesma letra nas colunas, não diferem entre si, pelo teste de Tukey, a 5\% de probabilidade.

A variação de fertilidade do solo, em função do uso das diferentes leguminosas nas entrelinhas do cafeeiro, estão apresentadas na Tabela 1 . Os resultados mostram que o tratamento com Flemingia congesta, aumentou significativamente os teores de cálcio no solo, ocorrendo o mesmo para soma de bases onde também foi observado um acréscimo significativo.

Segundo Lopes (1999) a concentração de cálcio na fitomassa da Flemingia congesta é de 7,0 gramas/kg, valor semelhante às de outras leguminosas tropicais. Canto (1989) estudando os efeitos da introdução de leguminosas de cobertura em plantios comerciais de guaraná também encontrou valores médios semelhantes dos teores de nutrientes minerais na parte aérea entre as espécies Flemingia congesta e Mucuna cocbinchinensis onde os percentuais de $\mathrm{K}, \mathrm{Ca}$ e $\mathrm{Mg}$ foram de 0,85, 0,56 e 0,15 para a Flemingia e $0,93,0,53$ e 0,53 para a Mucuna respectivamente.

Provavelmente este acréscimo nos teores de cálcio e soma de bases tenha se dado mais em função da produtividade maior de fitomassa da Flemingia congesta em relação às outras utilizadas no experimento e principalmente por ser um arbusto perene, com raízes profundas, o que pode ser vantajoso, melhorando a aeração do solo e a reciclagem de nutrientes (Canto, 1989).

Os teores médios de $\mathrm{N}$ encontrados nas folhas dos cafeeiros, avaliadas em maio de 2002 (Tabela 2), mostrou que não houve diferença significativa entre as leguminosas estudadas. Os percentuais variaram de 2,61\% (Canavalia ensiformis) a 3,15\% (Flemingia congesta).

Isto provavelmente aconteceu devido ao pouco tempo de estabelecimento das leguminosas nas entrelinhas dos cafeeiros. Por outro lado, ocorreu diferença significativa para os percentuais médios de $\mathrm{N}$ nas folhas dos cafeeiros com relação à adubação nitrogenada. Neste caso, os cafeeiros que não 


\section{ACTA AMAZONICA}

Tabela 1 - Características químicas de amostras de solo $(0-20 \mathrm{~cm})$ coletadas nas entrelinhas de cafeeiros, cultivadas com leguminosas. Média de quatro repetições. Rio Branco, AC, 2003.

\begin{tabular}{lccccc}
\hline \hline Características & \multicolumn{5}{c}{ Leguminosas } \\
\cline { 2 - 6 } químicas & C.cajan & C.ensiformis & F. congesta & M.aterrima & Testemunha \\
\hline $\mathrm{PH}(\mathrm{H} 2 \mathrm{O})$ & $4,1 \mathrm{a}$ & $4,2 \mathrm{a}$ & $4,2 \mathrm{a}$ & $4,1 \mathrm{a}$ & $4,2 \mathrm{a}$ \\
Soma bases (cmolc/dm3) & $2,12 \mathrm{~b}$ & $2,33 \mathrm{~b}$ & $3,09 \mathrm{a}$ & $2,21 \mathrm{~b}$ & $2,00 \mathrm{~b}$ \\
$\mathrm{CTC}(\mathrm{cmolc} / \mathrm{dm3})$ & $9,1 \mathrm{a}$ & $8,8 \mathrm{a}$ & $10,1 \mathrm{a}$ & $9,5 \mathrm{a}$ & $8,7 \mathrm{a}$ \\
V\% & $23,1 \mathrm{a}$ & $26,0 \mathrm{a}$ & $30,2 \mathrm{a}$ & $23,1 \mathrm{a}$ & $22,8 \mathrm{a}$ \\
Teor Carbono $(\mathrm{dag} / \mathrm{kg})$ & $0,75 \mathrm{a}$ & $0,87 \mathrm{a}$ & $0,67 \mathrm{a}$ & $0,90 \mathrm{a}$ & $0,85 \mathrm{a}$ \\
Teor M.O (dag/kg) & $1,35 \mathrm{a}$ & $1,55 \mathrm{a}$ & $1,20 \mathrm{a}$ & $1,57 \mathrm{a}$ & $1,50 \mathrm{a}$ \\
$\mathrm{H}+\mathrm{Al}(\mathrm{cmolc} / \mathrm{dm} 3)$ & $6,99 \mathrm{a}$ & $6,52 \mathrm{a}$ & $7,09 \mathrm{a}$ & $7,32 \mathrm{a}$ & $6,76 \mathrm{a}$ \\
$\mathrm{P}(\mathrm{mg} / \mathrm{dm} 3)$ & $1,77 \mathrm{a}$ & $1,90 \mathrm{a}$ & $2,00 \mathrm{a}$ & $2,37 \mathrm{a}$ & $2,07 \mathrm{a}$ \\
$\mathrm{K}(\mathrm{mg} / \mathrm{dm} 3)$ & $0,44 \mathrm{a}$ & $0,35 \mathrm{a}$ & $0,36 \mathrm{a}$ & $0,47 \mathrm{a}$ & $0,37 \mathrm{a}$ \\
$\mathrm{Mg}(\mathrm{cmolc} / \mathrm{dm} 3)$ & $0,54 \mathrm{a}$ & $0,59 \mathrm{a}$ & $0,71 \mathrm{a}$ & $0,55 \mathrm{a}$ & $0,51 \mathrm{a}$ \\
Ca $(\mathrm{cmolc} / \mathrm{dm} 3)$ & $1,13 \mathrm{~b}$ & $1,37 \mathrm{~b}$ & $2,01 \mathrm{a}$ & $1,18 \mathrm{~b}$ & $1,12 \mathrm{~b}$ \\
\hline \hline
\end{tabular}

Médias seguidas de mesma letra na linha, pertencem a um mesmo grupo, de acordo com o critério de agrupamento de Scott-Knott, a 5\% de probabilidade.

Tabela 2 - Efeito do consórcio café $\mathrm{x}$ leguminosas nos teores médios de $\mathrm{N}$ encontrados nas folhas dos cafeeiros. Rio Branco, AC, 2002.

\begin{tabular}{llll}
\hline \hline \multicolumn{4}{c}{$\%$ de $N^{1}$} \\
Leguminosas & $\begin{array}{l}\text { Sem } \\
\text { adubação }\end{array}$ & $\begin{array}{l}\text { Com } \\
\text { Adubação }\end{array}$ & Médias \\
Feijão Guandu & $2,40 \mathrm{a}$ & $3,12 \mathrm{a}$ & $2,76 \mathrm{a}$ \\
Feijão de Porco & $2,27 \mathrm{a}$ & $2,95 \mathrm{a}$ & $2,61 \mathrm{a}$ \\
Flemingia & $2,55 \mathrm{a}$ & $3,76 \mathrm{a}$ & $3,15 \mathrm{a}$ \\
Mucuna Preta & $3,05 \mathrm{a}$ & $2,78 \mathrm{a}$ & $2,91 \mathrm{a}$ \\
Testemunha & $2,75 \mathrm{a}$ & $3,03 \mathrm{a}$ & $2,89 \mathrm{a}$ \\
Médias & $2,60 \mathrm{~B}$ & $3,12 \mathrm{~A}$ & 2,86 \\
\hline \hline
\end{tabular}

${ }^{1}$ Médias seguidas de mesma letra, minúscula nas colunas e maiúscula na linha, pertencem a um mesmo grupo, de acordo com o critério de agrupamento de Scott-Knott, a 5\% de probabilidade.

receberam a adubação nitrogenada apresentaram um percentual médio deste elemento nas folhas de $2,60 \%$, enquanto que aqueles que receberam adubação apresentaram percentual médio de 3,12\%. Este último percentual encontra-se dentro dos limites considerados ideais por Andrade (2001) que estabelece como adequados valores entre 2,7 a 3,2\% de $\mathrm{N}$ nas folhas do cafeeiro.

$\mathrm{Na}$ avaliação da infestação das plantas invasoras, realizada no final de 2002, o tratamento com Flemingia congesta destacou-se das demais proporcionando uma cobertura total do solo, evitando a infestação por invasoras nas entrelinhas. Esta constatação esta de acordo com as conclusões de Canto (1989) no estudo sobre os efeitos da introdução de leguminosas de cobertura em plantios comerciais de guaraná no Estado do Amazonas, onde afirma que as leguminosas Flemingia congesta e Desmodium ovalifolium, embora com desenvolvimento inicial lento, foram as que apresentaram maior resistência a cortes e melhor capacidade de rebrota $\mathrm{e}$ que após o segundo corte essas espécies tendem a formar uma densa capa sobre o solo, evitando o aparecimento de plantas invasoras e protegendo-o dos efeitos dos raios solares e das chuvas, proporcionando com isso uma menor temperatura e maior retenção de água. Os demais tratamentos utilizados (Sem leguminosa, Mucuna aterrima, Cajanus cajan, e Canavalia ensiformis), quando comparados estatisticamente entre si não mostraram diferenças e não reduziram o índice de infestação de plantas invasoras. As médias do peso seco das plantas invasoras para um área de $2 \mathrm{~m}^{2}$ para estes tratamentos são apresentadas na Tabela 3 .

Uma provável explicação para a não redução do índice de infestação de plantas invasoras nas entrelinhas dos cafeeiros seria a relação $\mathrm{C} / \mathrm{N}$ baixa das leguminosas usadas nas entrelinhas do experimento, citada por Brasil (2000) e Lopes (1999) como sendo ao redor de $20 / 1$. Esta baixa relação $\mathrm{C} / \mathrm{N}$ permitiu uma decomposição rápida da matéria verde espalhada nas entrelinhas e, ainda, ao longo período entre o seu corte, em

Tabela 3 - Médias do peso seco das plantas invasoras para uma área de $2 \mathrm{~m}^{2}$. Rio Branco, AC, 2002.

\begin{tabular}{ll}
\hline \hline & $\left(\mathrm{g} / 2 \mathrm{~m}^{2}\right)$ \\
\hline Leguminosas & Médias \\
Testemunha & $169 \mathrm{a}$ \\
Mucuna Preta & $221 \mathrm{a}$ \\
Feijão Guandu & $292 \mathrm{a}$ \\
Feijão de Porco & $384 \mathrm{a}$ \\
Média & 267 \\
\hline \hline
\end{tabular}

1 Médias seguidas de mesma letra na coluna pertencem a um mesmo grupo, de acordo com o critério de agrupamento de Scott-Knott, a 5\% de probabilidade. 
abril, (final da época das chuvas) e seu novo replantio, por sementes, no início do período chuvoso em outubro. Este intervalo permitiu a re-infestação quase que indistintamente, não permitindo a observação de diferenças entre os tratamentos com leguminosas, exceto a Flemingia congesta. Com relação a testemunha, que apresentou um dos menores índices de infestação, depois da Flemingia congesta, justifica-se o fato por não ter havido deposição de matéria verde sob o solo, a exemplo dos demais tratamentos, permanecendo ali somente as invasoras pioneiras, mas sem esta adição de matéria orgânica estimuladora de processos químicos e biológicos favoráveis ao desenvolvimento das plantas.

Em função do rápido crescimento da Flemingia congesta e sua capacidade de rebrote da touceira remanescente esta foi a única leguminosa submetida à dois cortes num período de 12 meses. Isto proporcionou uma melhor cobertura do solo durante todo ano, explicando sua capacidade de reduzir a invasão por invasoras. Este processo é caracterizado por Monegat (1991) como "abafamento" sendo seu controle influenciado pelos seguintes aspectos das plantas de cobertura: agressividade inicial, volume de massa seca e verde, porte (ereto ou prostado), distribuição dos resíduos sobre o terreno e velocidade de decomposição (relação $\mathrm{C} / \mathrm{N}$ ).

\section{CONCLUSÕES}

a) A produtividade dos cafeeiros aumentou, independente ou não do uso de adubação nitrogenada, quando utilizou-se as leguminosas Flemingia congesta e Mucuna aterrima. Entretanto, com o uso combinado dessas leguminosas com adubação nitrogenada os cafeeiros tornaram-se mais altos e frondosos.

b) O desenvolvimento da altura de plantas e do diâmetro da copa dos cafeeiros foi negativamente afetado quando utilizou-se a Canavalia ensiformis.

c) Os teores de cálcio e valor da soma de bases aumentaram significativamente quando se utilizou a Flemingia congesta.

d) AFlemingia congesta, devido sua capacidade de rebrote, foi a única leguminosa que controlou eficientemente as plantas invasoras nas entrelinhas dos cafeeiros.

\section{BIBLIOGRAFIA CITADA}

Andrade, C.E. de. 2001. Calagem e adubação do café. Aprenda Fácil. Viçosa. 130p.

Bertoni, J; Neto, F.L. 1993. Conservação do Solo, $3^{\text {a }}$ Edição, Editora Ícone. São Paulo, SP. 355p.
Brasil. 2000. Ministério da Agricultura e do Abastecimento. Programa de crédito para a agricultura orgânica no Acre. Rio Branco, AC: paginação irregular.

Canto, A. do C. 1989. Importância ecológica do uso de leguminosas como plantas de cobertura em guaranazais no Estado do Amazonas. Tese Doutorado. INPA/FUA. Manaus. 121p.

Carvajal, J.F. 1984. Cafeto: cultivo y fertilización. Instituto Internacional de la Potasa. Berna, Suiza. 254p.

Gomes, T.C. de A .; Moraes, R.N. de S. 1997. Recomendações para o plantio de espécies leguminosas para o manejo de solos no Acre. EMBRAPA. Rio Branco, Acre. 3p. (EMBRAPA ACRE. Comunicado Técnico, 77).

Gomes, T.C. de A; Avila Paz, F. das C.; Dedecek, R.A.; Freitas, P.L. de; Rego, R.S. 1990. Determinação de perdas de solo e água em diferentes condições de solo e manejo em Rio Branco-AC. EMBRAPA UEPAE Rio Branco. 8p. (EMBRAPAUEPAE Rio Branco. Pesquisa em Andamento, 67).

Guimarães, P.T.G.; Nogueira, F.D.; Lima, P.C. de; Guimarães, M.J.C.L.; Pozza, A.A.A. 2002. Adubação e nutrição do cafeeiro em sistema orgânico de produção. Informe Agropecuário, Belo Horizonte, 23, (214/215): 63-81.

Lopes, A. S.; Guimarães, P. T. G.; coord. 1989. Recomendações para o uso de corretivos e fertilizantes em Minas Gerais; $4^{\mathrm{a}}$ aproximação. CFSEMG. Lavras, MG. 176 p.

Lopes, V.M.B. 1999. Velocidade de decomposição da fitomassa de Puerária phaseolides, Desmodium ovalifolium $e$ Flemingia congesta em um sistema agroflorestal. Dissertação Mestrado. UFAC. Rio Branco. 66p.

Monegat, C. 1991. Plantas de cobertura do solo: Características e manejo em pequenas propriedades. $2^{\mathrm{a}}$ Edição, Chapecó, SC. $337 \mathrm{p}$.

Ricci, M. dos S.F.; Aguiar, L.A. de. 2003. Influência da adubação verde sobre o crescimento, produtividade e teor de nitrogênio no tecido foliar do cafeeiro (Coffea arabica L.) sob manejo orgânico. In: SIMPÓSIO DE PESQUISA DOS CAFÉS DO BRASIL, 3., 2003, Brasília. Anais...Brasília: Embrapa Café. p.420-421.

Vale, F. R. do; Guedes, G. A.; Guilherme, L. R. G. 1995. Manejo da fertilidade do solo. UFLA/FAEPE. Lavras, MG. 206 p.

\author{
RECEBIDO EM 12/09/2003 \\ ACEITO EM 26/12/2005
}

